\title{
Biodegradation Study of Nanocomposites of Phenol Novolac Epoxy/Unsaturated Polyester Resin/Egg Shell Nanoparticles Using Natural Polymers
}

\author{
S. M. Mousavi, ${ }^{1}$ H. Esmaeili, ${ }^{2}$ O. Arjmand, ${ }^{3}$ Sh. Karimi, ${ }^{1}$ and S. A. Hashemi ${ }^{4}$ \\ ${ }^{1}$ Department of Chemical Engineering, School of Chemical and Petroleum Engineering, Shiraz University, Shiraz 71345-1789, Iran \\ ${ }^{2}$ Engineering Department, Islamic Azad University of Bushehr, Bushehr 19555-75196, Iran \\ ${ }^{3}$ Young Researchers and Elite Club, Nourabad Mamasani Branch, Islamic Azad University, Nourabad 81746-73441, Iran \\ ${ }^{4}$ Department of Mechanical Engineering, Islamic Azad University, Najafabad Branch, Najafabad 85141-43131, Iran
}

Correspondence should be addressed to S. M. Mousavi; kempo.smm@gmail.com

Received 14 June 2015; Revised 8 September 2015; Accepted 8 October 2015

Academic Editor: Da-Bin Liu

Copyright (C) 2015 S. M. Mousavi et al. This is an open access article distributed under the Creative Commons Attribution License, which permits unrestricted use, distribution, and reproduction in any medium, provided the original work is properly cited.

\begin{abstract}
Nanocomposite materials refer to those materials whose reinforcing phase has dimensions on a scale from one to one hundred nanometers. In this study, the nanocomposite biodegradation of the phenol Novolac epoxy and the unsaturated polyester resins was investigated using the egg shell nanoparticle as bioceramic as well as starch and glycerin as natural polymers to modify their properties. The phenol Novolac epoxy resin has a good compatibility with the unsaturated polyester resin. The prepared samples with different composition of materials for specified time were buried under soil and their biodegradation was studied using FTIR and SEM. The FTIR results before and after degradation showed that the presence of the hydroxyl group increased the samples degradation. Also adding the egg shell nanoparticle to samples had a positive effect on its degradation. The SEM results with and without the egg shell nanoparticle also showed that use of the egg shell nanoparticle increases the samples degradation. Additionally, increasing the amount of starch, and glycerol and the presence of egg shell nanoparticles can increase water adsorption.
\end{abstract}

\section{Introduction}

Nanocomposite materials referred to those materials whose reinforcing phase has dimensions on a scale from one to one hundred nanometers, such as polymer-ceramic, polymermetal, ceramic-metal, and ceramic-ceramic nanocomposites. A nanometric reinforcer, due to the very small dimensions and very high surface compared to the conventional reinforcers, improves the desired properties at a lower load level and is a good alternative to conventional composites. Epoxy resins were discovered and recorded in Germany in 1980 [1]. Epoxy resins are an important class of polymeric materials that are characterized by the presence of three-member ring containing epoxy, epoxide, and Ethoxylate. The epoxy resin that is formed as a multicomponent polymer network is built from the internal cross-linked polymer chains [2]. The Novolac phenol epoxy is able to mix and adapt with unsaturated polyester and it is found that, after mixing and annealing (sintering), the strength and impact resistance of the resin increases considerably. The first reason of epoxy resins compatibility with unsaturated polyester resin (UPR) is their polarity $[3,4]$. The terminal hydroxyl and carboxyl groups in UPR lead to increasing the chain length and crosslinking (length) during the curing process of epoxy resin, as a catalyst. The hydroxyl groups formed in this reaction are able to react with epoxide groups $[5,6]$. Products prepared from polymer nanocomposites have many applications at various industries such as chemical, automotive, construction, military, medical, home appliances, sports, agriculture, and electronics and these reduce the fuel and energy consumption, increase safety and resistance against earthquakes and fires, extend the life of structures, reduce losses caused by storage of food and agricultural products, reduce losses due to corrosion, and briefly can lead to an efficient use of existing 
resources [7, 8]. However, despite having numerous applications of polymer nanocomposites, disposal of their waste can cause serious damages to the nature and environment, as well as affecting the costs which can lead to a serious challenge for polymer industry. For the first time in 1973, starch was introduced by Griffin as an effective additive to make plastics biodegradable [9]. His subsequent researches showed that using starch can be an acceptable way to increase the biodegradation of polymers [10]. The main reasons that make the polymers nonbiodegradable (for nonbiodegradation of polymers) are their high molecular weight and the strong bond between their monomers. Nowadays, various kinds of biodegradable polymers are identified and their number is increasing day by day [11]. The biodegradable materials are the materials that are easily decomposed to their subblocks by the action of microorganisms and do not remain in the environment. Biodegradable polymers are macromolecules that undergo chemical modification by physical-chemical factors and microorganisms, resulting in the formation of lower molecular weight components [12]. Recently, extensive studies are investigated for preparation of polymer blends containing various amounts of starch to replace them with polymers, especially in the packaging industry [13]. Starch is a natural, cheap, renewable, and biodegradable material and also a kind of natural carbohydrate that is formed from the branched-amylopectin molecules and linear polysaccharide molecules called amylose. Adding starch to polyolefins applies the general effects of fillers which increase the resistance of polyolefins on the properties of polymers. When these compounds are exposed to soil, starch compounds, as the biodegradable components, are easily decomposed by microorganisms, leading to increasing the porosity and then to decreasing the plastic matrix resistance gradually and consequently to break the plastic matrix to smaller parts [14]. The objective of this study was to investigate the biodegradation of Novolac phenol epoxy resin and unsaturated polyester nanocomposites using natural polymers and egg shell nanoparticles. For this purpose, the morphological and structural properties of samples were analyzed by SEM and the biodegradation of the samples was also investigated by FTIR.

\section{Experimental}

2.1. Materials. The phenol Novolac epoxy resin was purchased from COMEYL Company (Iran) and unsaturated polyester resin, methyl ethyl ketone peroxide, and cobalt naphthenate were purchased from the chemical industry company of Bushehr city (Iran). The mechanical and chemical properties of these materials are tabulated as polyester, methyl ethyl peroxide, or (hardener) cobalt naphthenate in Tables 1-3. Table 4 gives the properties of starch. Glycerol used in this study is an edible glycerol and was purchased from Mojallali Company (Iran), whose properties are tabulated in Table 5.

2.1.1. Egg Shell Nanoparticles. The eggshells were powdered by Ball Mill machine and then the size of egg shell nanoparticles was determined by solving them in an ethylene glycol
TABLE 1: The mechanical and chemical properties of polyester.

\begin{tabular}{lc}
\hline Properties & Value \\
\hline The gelation time for 0.5 weight percent of & \\
CO and 2 weight percent of methyl ethyl & $10-15(\mathrm{~min})$ \\
ketone peroxide & \\
The hardness time after gel formation & $8-15(\mathrm{~min})$ \\
The hardness temperature & $190^{\circ} \mathrm{C}$ \\
Solid percent & $64 \pm 2 \%$ \\
Viscosity at $25^{\circ} \mathrm{C}$ & $600-450(\mathrm{cp})$ \\
Acid number & $18-24(\mathrm{mgKOH} / \mathrm{g})$ \\
\hline
\end{tabular}

TABLE 2: The mechanical and chemical properties of methyl ethyl peroxide.

\begin{tabular}{lc}
\hline Properties & Value \\
\hline Appearance & Colorless liquid \\
Reactive oxygen & $9.5 \% \mathrm{~W} / \mathrm{W}$ \\
Density at $20^{\circ} \mathrm{C}$ & $1.02\left(\mathrm{~g} / \mathrm{cm}^{3}\right)$ \\
Viscosity at $20^{\circ} \mathrm{C}$ & $13(\mathrm{mpa} \cdot \mathrm{s})$ \\
Critical temperature & $60^{\circ} \mathrm{C}$ \\
The lowest storage temperature & $-25^{\circ} \mathrm{C}$ \\
The best storage temperature & Under $30^{\circ} \mathrm{C}$ \\
\hline
\end{tabular}

TABLE 3: The mechanical and chemical properties of cobalt naphthenate.

\begin{tabular}{lc}
\hline Properties & Value \\
\hline Appearance & Blue liquid tends to violet \\
The amount of cobalt & $4 \pm 0.05 \%$ \\
Diluent & Toluene \\
Density at $25^{\circ} \mathrm{C}$ & $0.99\left(\mathrm{~g} / \mathrm{cm}^{3}\right)$ \\
Viscosity at $20^{\circ} \mathrm{C}$ & $300(\mathrm{mPa} \cdot \mathrm{s})$ \\
\hline
\end{tabular}

TABLE 4: The mechanical and chemical properties of starch.

\begin{tabular}{lc}
\hline Properties & Value \\
\hline Molecular formula & $\left(\mathrm{C}_{6} \mathrm{H}_{10} \mathrm{O}_{5}\right)_{n}$ \\
Appearance & White powder \\
Density & $1 / 5 \mathrm{~g} / \mathrm{cm}^{3}$ \\
Melting point & Decomp. \\
\hline
\end{tabular}

TABLE 5: The mechanical and chemical properties of glycerol.

\begin{tabular}{lc}
\hline Properties & Value \\
\hline Molecular formula & $\mathrm{C}_{3} \mathrm{H}_{8} \mathrm{O}_{3}$ \\
Molecular weight & $92.10 \mathrm{~g} / \mathrm{mol}$ \\
Density & 1.26 \\
Moisture & $>2.0 \%$ \\
\hline
\end{tabular}

solvent. The size of the nanoparticles is obtained as $70 \mathrm{~nm}$. Figure 1 shows nanoparticle size distribution of the egg shell.

2.2. Samples Analysis. To evaluate the morphological and structural properties of materials, the Scanning Electron 
TABLE 6: The characteristics of the prepared samples.

\begin{tabular}{lccccc}
\hline Sample & $\begin{array}{c}\text { Unsaturated polyester } \\
\text { (gr) }\end{array}$ & $\begin{array}{c}\text { Phenol Novolac } \\
\text { epoxy } \\
\text { (weight percent) }\end{array}$ & $\begin{array}{c}\text { Glycerol } \\
\text { (weight percent) }\end{array}$ & $\begin{array}{c}\text { Starch } \\
\text { (weight percent) }\end{array}$ & $\begin{array}{c}\text { Egg shell nanoparticles } \\
\text { (weight percent) }\end{array}$ \\
\hline 1 & 50 & 10 & 0 & 0 & 0 \\
2 & 50 & 10 & 5 & 0 & 20 \\
3 \\
4 & 50 & 10 & 5 & 20 & 0 \\
5 & 50 & 10 & 15 & 20 & 1 \\
6 & 50 & 10 & 5 & 20 & 3 \\
7 & 50 & 10 & 15 & 20 & 3 \\
8 & 50 & 10 & 5 & 20 & 3 \\
9 & 50 & 10 & 15 & 20 & 4 \\
10 & 50 & 10 & 5 & 20 & 4 \\
\hline
\end{tabular}

Microscope (SEM, Tescan VEGA-П) system was used. In SEM, electrons collide to the surface sample that already is coated by a thin layer (usually gold) with an approximate thickness of 100-500 angstroms. To investigate the biodegradation of the samples, Fourier Transform Infrared Spectroscopy (FTIR) was also used.

2.3. Methodology. Before preparing the samples, starch was placed in an oven at temperature of $70^{\circ} \mathrm{C}$ for $24 \mathrm{hr}$ for removing its moisture. The dried starch and glycerol were then mixed with glycerol to starch ratio of $10: 1$. Loosening the starch with glycerol leads to improving the process ability and flexibility of the mixtures; phenol Novolac epoxy resin was mixed separately with egg shell nanoparticles for $15 \mathrm{~min}$ using a mechanical mixer. The phenol Novolac epoxy resin containing egg shell nanoparticles was mixed with unsaturated polyester, starch, and glycerol in different percentages of composition using Sonicator Machine. Phenol Novolac epoxy resin at room temperature was (sintered) cured (using methyl ethyl ketone and peroxide dimethyl phthalate containing 60 percent peroxide and reaction accelerator). Phenol Novolac epoxy resin contents were 5 and 10 and 15 weight percent. The characteristics of the samples are shown in Table 6. The final sintering was performed at temperature $80^{\circ} \mathrm{C}$ for 3 hours. The mixture should be well stirred to obtain a homogeneous liquid. After sintering (curing), the samples were put in the oven at specified time and temperature. After the samples were accurately weighed, for a better penetration of moisture and microorganisms, the samples were buried in an appropriate depth. After 2 and 10 months, the samples were unearthed and washed with water and ethanol. Finally, the samples were dried in vacuum at temperatures of $40^{\circ} \mathrm{C}$ to reach a constant weight.

$M_{0}$ and $M_{d}$ are the samples weight before and after degradation, respectively. Then, in order to perform the FTIR test and microscopy investigation SEM tests (Figure 7) including test of samples 3 in Figure 7(a) and 7 in Figure 7(b), before and after the degradation, and to absorb the moisture, the samples were cut in specific sizes. The characteristics of the prepared samples are shown in Table 6.

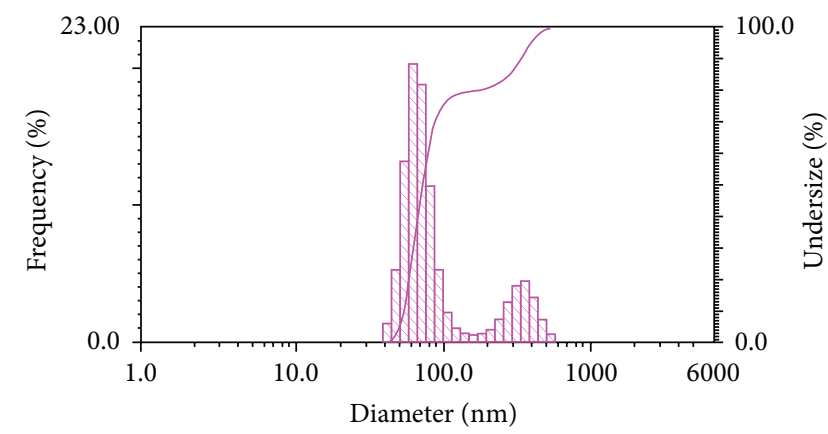

FIGURE 1: Diagram of nanoparticle size (PSA) of the egg shell nanoparticles.

\section{Results and Discussions}

3.1. Investigation of Water Adsorption of Phenol Novolac Epoxy Resin. The results of water adsorption are tabulated in Table 7. The results show that increasing the amount of starch and also the presence of egg shell nanoparticles can increase water adsorption. This increase is due to the hydrophilic property of nanoparticles and their uniform distribution in the polymer matrix. According to Table 7, it can be concluded that the increasing of glycerol weight percent increases the water adsorption. Additionally, with comparison of samples 2 and 3, it can be said that the increasing of starch weight percent will increase the amount of water adsorption. The water adsorption percent can be calculated by

$$
\text { Water adsorption percent }=\left[\frac{\left(M_{0}-M_{d}\right)}{M_{0}}\right] \times 100,
$$

where $m_{1}$ and $m_{2}$ are the weight of the sample before and after process, respectively.

Also, to show the effect of the egg shell nanoparticle on water adsorption of samples, diagram of sample water adsorption percent versus time is shown in Figure 2. By comparing samples $4,6,8$, and 10 , it can be concluded that the presence of nanoparticles will increase the weight of the samples because of water adsorption. 
TABLE 7: Weight change of the samples due to their water absorption after 14 days' time (day).

\begin{tabular}{|c|c|c|c|c|c|c|c|c|c|c|}
\hline \multirow{2}{*}{ Time (day) } & \multicolumn{10}{|c|}{ Sample } \\
\hline & 1 & 2 & 3 & 4 & 5 & 6 & 7 & 8 & 9 & 10 \\
\hline 1 & 2.901 & 2.885 & 3.075 & 3.136 & 3.419 & 3.445 & 3.644 & 3.648 & 4.167 & 4.174 \\
\hline 2 & 2.902 & 2.887 & 3.078 & 3.139 & 3.437 & 3.463 & 3.672 & 3.695 & 4.185 & 4.214 \\
\hline 3 & 2.901 & 2.886 & 3.081 & 3.144 & 3.448 & 3.474 & 3.689 & 3.711 & 4.209 & 4.236 \\
\hline 4 & 2.903 & 2.888 & 3.083 & 3.148 & 3.459 & 3.482 & 3.723 & 3.741 & 4.217 & 4.251 \\
\hline 5 & 2.903 & 2.889 & 3.086 & 3.152 & 3.461 & 3.501 & 3.736 & 3.769 & 4.235 & 4.269 \\
\hline 6 & 2.902 & 2.888 & 3.085 & 3.156 & 3.479 & 3.518 & 3.751 & 3.784 & 4.253 & 4.287 \\
\hline 7 & 2.902 & 2.887 & 3.089 & 3.154 & 3.495 & 3.539 & 3.778 & 3.796 & 4.279 & 4.315 \\
\hline 8 & 2.903 & 2.888 & 3.093 & 3.159 & 3.506 & 3.554 & 3.795 & 3.813 & 4.292 & 4.331 \\
\hline 9 & 2.904 & 2.888 & 3.098 & 3.162 & 3.516 & 3.571 & 3.825 & 3.834 & 4.318 & 4.347 \\
\hline 10 & 2.901 & 2.889 & 3.104 & 3.16 & 3.536 & 3.586 & 3.857 & 3.879 & 4.335 & 4.371 \\
\hline 11 & 2.903 & 2.889 & 3.106 & 3.168 & 3.537 & 3.599 & 3.871 & 3.895 & 4.359 & 4.384 \\
\hline 12 & 2.903 & 2.888 & 3.108 & 3.169 & 3.538 & 3.604 & 3.932 & 3.964 & 4.362 & 4.399 \\
\hline 13 & 2.903 & 2.89 & 3.11 & 3.171 & 3.545 & 3.608 & 3.969 & 3.977 & 4.416 & 4.427 \\
\hline 14 & 2.905 & 2.89 & 3.112 & 3.176 & 3.545 & 3.608 & 3.987 & 3.997 & 4.439 & 4.441 \\
\hline
\end{tabular}

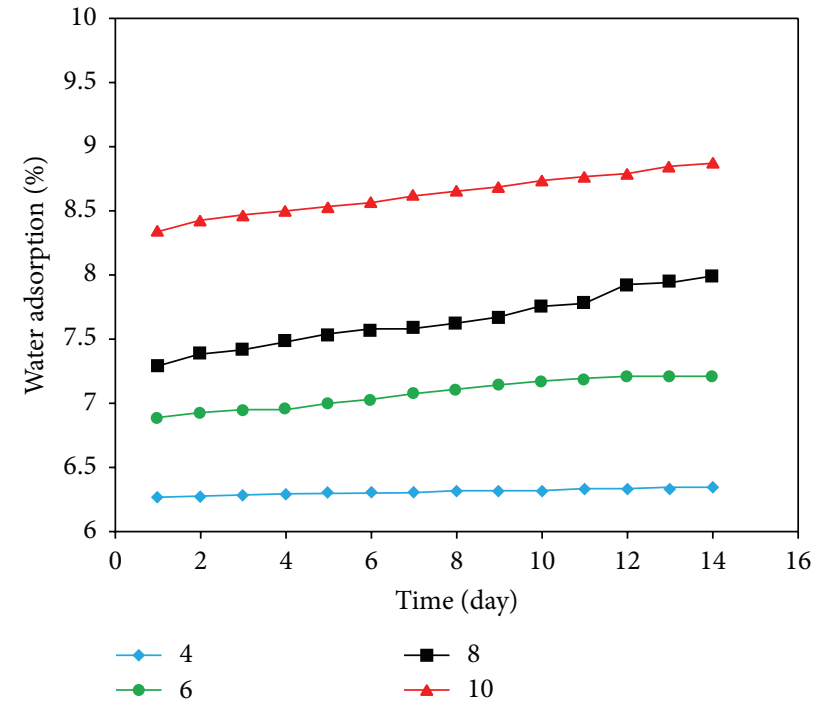

FIGURE 2: Diagram of water adsorption percentage of $4,6,8$, and 10 samples versus time.

3.2. FITR Analysis. Another way to confirm the biodegradation of the samples is to follow the created structural changes using FTIR spectroscopy. The presence of hydroxyl groups leads to increasing the samples degradation. To do so, Figure 3 shows the FTIR curves of samples 3, 7, and 9. Based on this figure, by increasing the number of $\mathrm{OH}-$ groups in the mixture, the absorption of hydroxyl groups is increased and so the pass percentage is decreased. Also, by reducing the number of hydroxyl groups in compounds with a low percentage of starch compounds, the absorption of hydroxyl groups is decreased considerably and the pass percentage is increased. In other words, by increasing the percentage of starch, glycerol, and egg shell nanoparticles in the mixture, the peak of the hydroxyl groups is increased

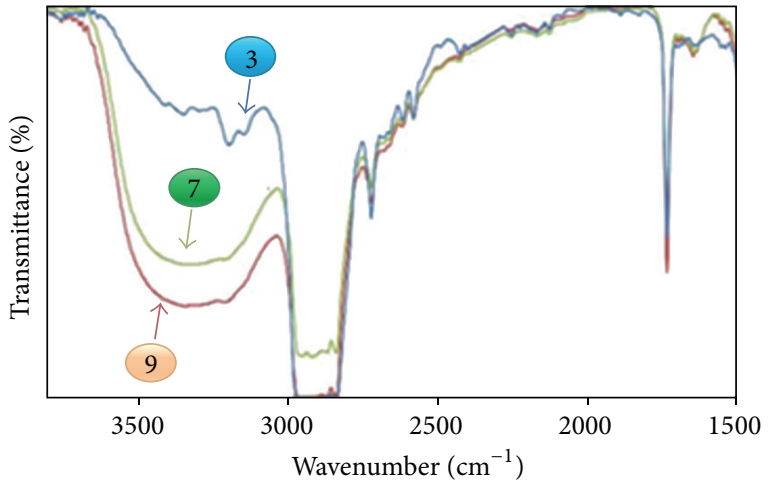

FIGURE 3: FTIR curves of samples 3, 7, and 9 before degradation.

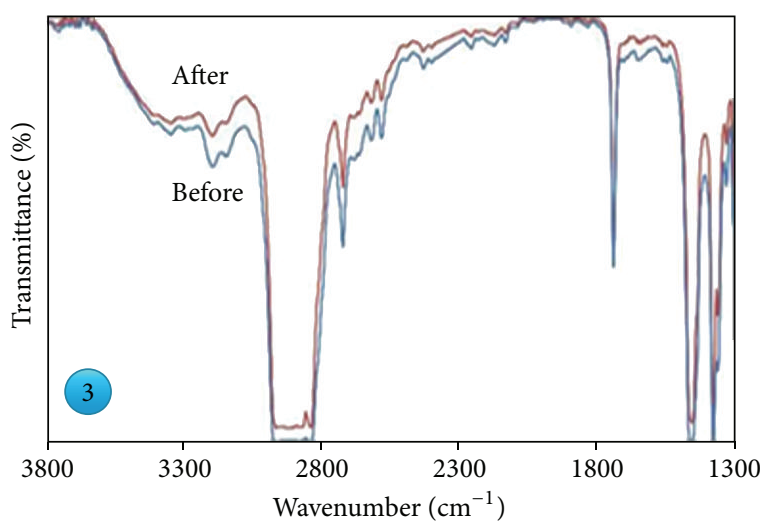

FIGURE 4: FTIR curves of sample 3 before and after the degradation.

in the wave numbers range of $3100-3600 \mathrm{~cm}^{-1}$. In addition, the FTIR curves of samples 3, 7, and 9, before and after the degradation of the samples, are shown in Figures 4, 5, and 6 , respectively. By comparing Figure 4 with Figures 5 and 6 , it can be concluded that the presence of starch enhanced 


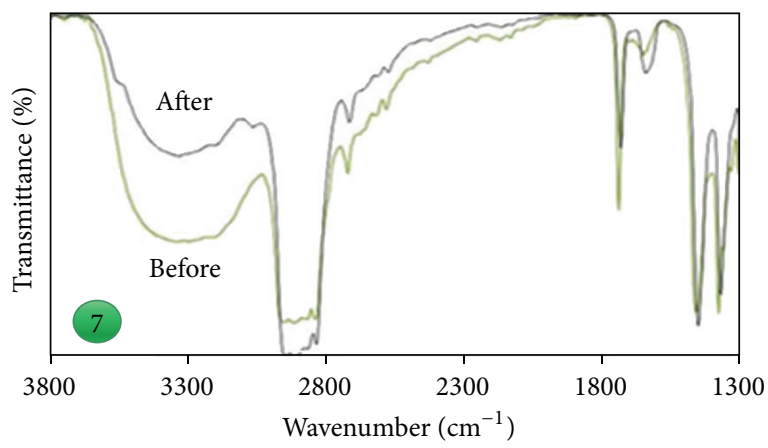

FIGURE 5: FTIR curves of sample 7 before and after the degradation.

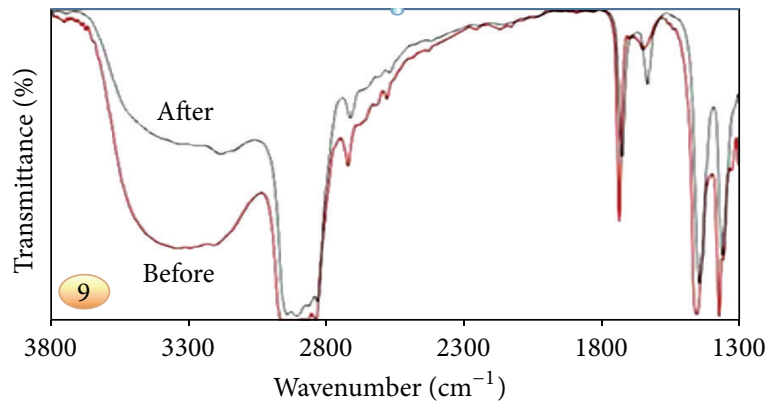

FIgURE 6: FTIR curves of sample 9 before and after the degradation.

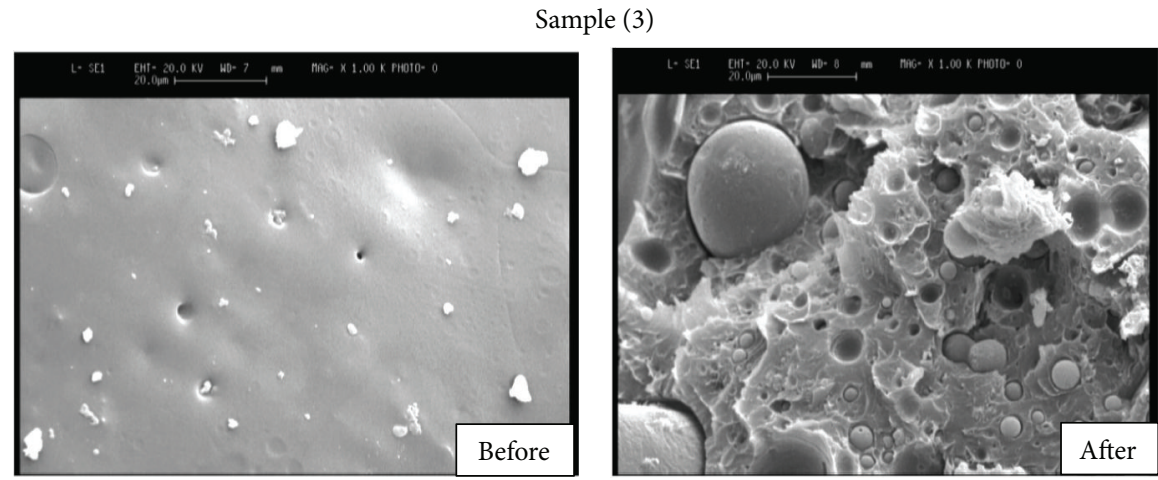

(a)

Sample (7)
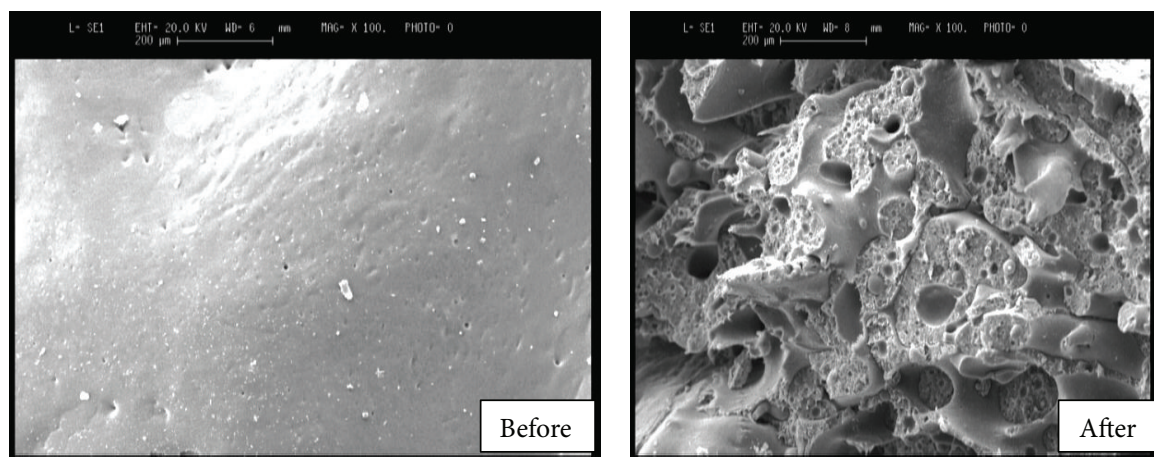

(b)

FIgURE 7: SEM test of samples 3 (a) and 7 (b), before and after the degradation. 
the FTIR light absorption. This reveals that the increase in light absorption increases the degradation level. A comparison between Figures 5 and 6 reveals that the sample with 3 wt.\% nanoparticle absorbs more light than the sample with 4 wt.\% nanoparticle. Because increasing the nanoparticle to $4 \mathrm{wt} . \%$ leads to accumulating the nanoparticles. Aggregation of nanoparticles makes samples lumpy and, therefore, it causes an increment in the light passage and, consequently, a reduction in samples degradation.

3.3. SEM Analysis. The surface identification and distribution of phenol Novolac epoxy resin, unsaturated polyester nanocomposites, egg shell nanoparticles, and natural polymers before and after degradation were carried out by SEM analysis. In the samples containing egg shell nanoparticles, starch, and phenol Novolac epoxy resin, which included unsaturated polyester resin, some differences can be seen (the bulge) at the fracture surface indicating a good connection between the egg shell nanoparticles, starch, glycerol, and polymer matrix. In samples 3 in Figure $7(a)$ and 7 in Figure $7(\mathrm{~b})$, before and after the degradation, this difference is reduced and the surface is smoother and, also, mechanical properties are decreased by 4 wt.\% with increasing the amount of starch and egg shell nanoparticles and decreasing glycerol. In fact, the optimal rate of egg shell nanoparticles, starch, and glycerol is obtained as $3 \mathrm{wt}$.\%. By comparing the morphology of the compounds before and after the process, it can be observed in all cases that the polymer samples were attacked by microorganisms, and the degradation effects of soil microorganisms on samples were more at a high percentage of starch and low percentage of glycerol.

\section{Conclusion}

In this paper, the biodegradation of nanocomposite using the phenol Novolac epoxy and the unsaturated polyester resins was studied. The effects of a nanobioceramic (the egg shell nanoparticle) and natural polymers (starch and glycerin) on the water adsorption of nanocomposite samples and also biodegradation of nanocomposite samples under soil were investigated. The results cleared that water adsorption increased in presence of egg shell nanoparticles. In addition, to study the biodegradation of nanocomposite samples under soil, FTIR and SEM were used. Their results revealed that the existence of hydroxyl group increased the samples degradation. Additionally, adding the egg shell nanoparticle to samples had a positive effect on its degradation.

\section{Conflict of Interests}

The authors declare that there is no conflict of interests regarding the publication of this paper.

\section{References}

[1] I. G. Farbenindustrie and P. Schlack, DE 676 117, 1938, US 2136 9281938.
[2] S. J. Hartman, The Epoxy Resin Formulators Training Manual, The Society of the Plastics Industry, New York, NY, USA, 1984.

[3] J. Zhang, J. Gao, X. Sun, Z. Peng, and J. Diao, "Preparation and characterization of $\mathrm{TiO}_{2}$ /poly (St-co-MAA) core/shell composite particles," Iranian Polymer Journal, vol. 16, no. 1, pp. 39-46, 2007.

[4] T. Suzuki, Y. Oki, M. Numajiri et al., "Novolac epoxy resins and positron annihilation," Journal of Applied Polymer Science, vol. 49, no. 11, pp. 1921-1929, 1993.

[5] K. P. Unnikrishnan and E. T. Thachil, "Aging and thermal studies on epoxy resin modified by epoxidized novolacs," Polymer-Plastics Technology and Engineering, vol. 45, no. 4, pp. 469-474, 2006.

[6] S. Li, F. Wang, Y. Wang, J. Wang, J. Ma, and J. Xiao, "Effect of acid and TETA modification on mechanical properties of MWCNTs/epoxy composites," Journal of Material Science, vol. 43, no. 8, pp. 2653-2658, 2008.

[7] G. Polizos, E. Tuncer, I. Sauers, and K. L. More, "Physical properties of epoxy resin/titanium dioxide nanocomposites," Polymer Engineering \& Science, vol. 51, no. 1, pp. 87-93, 2011.

[8] A. B. Cherian, L. A. Vargheseb, and E. T. Thachil, "Epoxymodified, unsaturated polyester hybrid networks," European Polymer Journal, vol. 43, no. 4, pp. 1460-1469, 2007.

[9] G. J. L. Griffin, "Particulate Starch Based Products," in Chemistry and Technology of Biodegradable Polymers, chapter 3, Springer Blackie Academic, London, UK, 1994.

[10] R. Chandra and R. Rustgi, “Biodegradable polymers," Progress in Polymer Science, vol. 23, no. 7, pp. 1273-1335, 1998.

[11] J. M. Castella, J. Urmenta, R. Lafuente, A. Navarrte, and R. Guerrero, "Biodegradation of poly(hydroxy alkanoate) in aerobic sediments," International Biodeterioration \& Biodegradation, vol. 74, p. 155, 1995.

[12] C. Bastoili and G. Floridi, "Starch-based biodegradable materials," in Proceeding of the Environmentally Degradable Polymers: Enviromental \& Biomedical Aspects, pp. 12-19, Antalya, Turkey, 1998.

[13] S. Kalambur and S. S. H. Rizvi, "An overview of starch-based plastic blends from reactive extrusion," Journal of Plastic Film and Sheeting, vol. 22, no. 1, pp. 39-58, 2006.

[14] D. S. Rosa, C. G. F. Guedes, and C. L. Carvalho, "Processing and thermal, mechanical and morphological characterization of post-consumer polyolefins/thermoplastic starch blends," Journal of Materials Science, vol. 42, no. 2, pp. 551-557, 2007. 

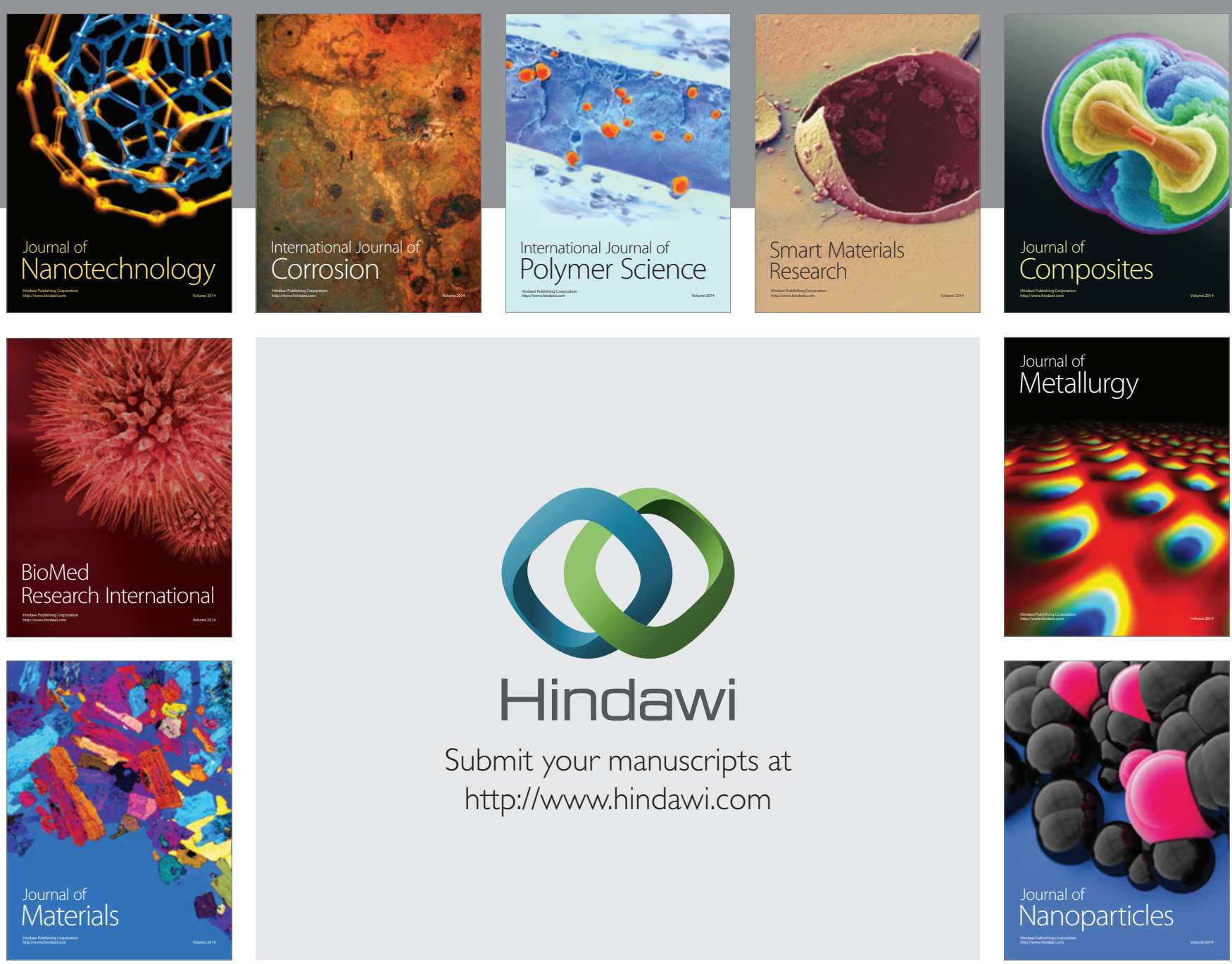

Submit your manuscripts at http://www.hindawi.com
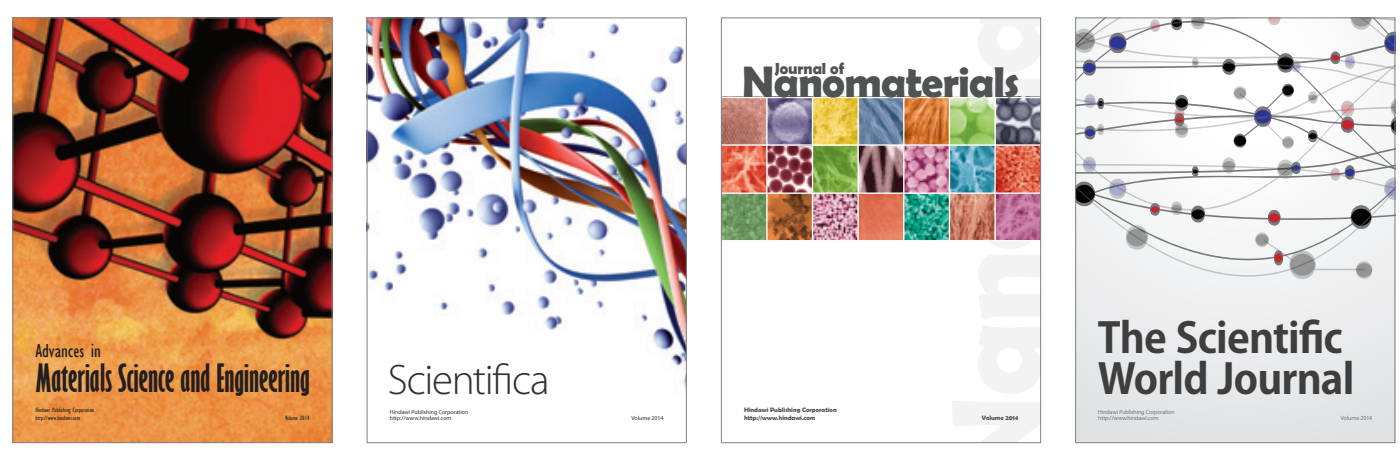

\section{The Scientific World Journal}
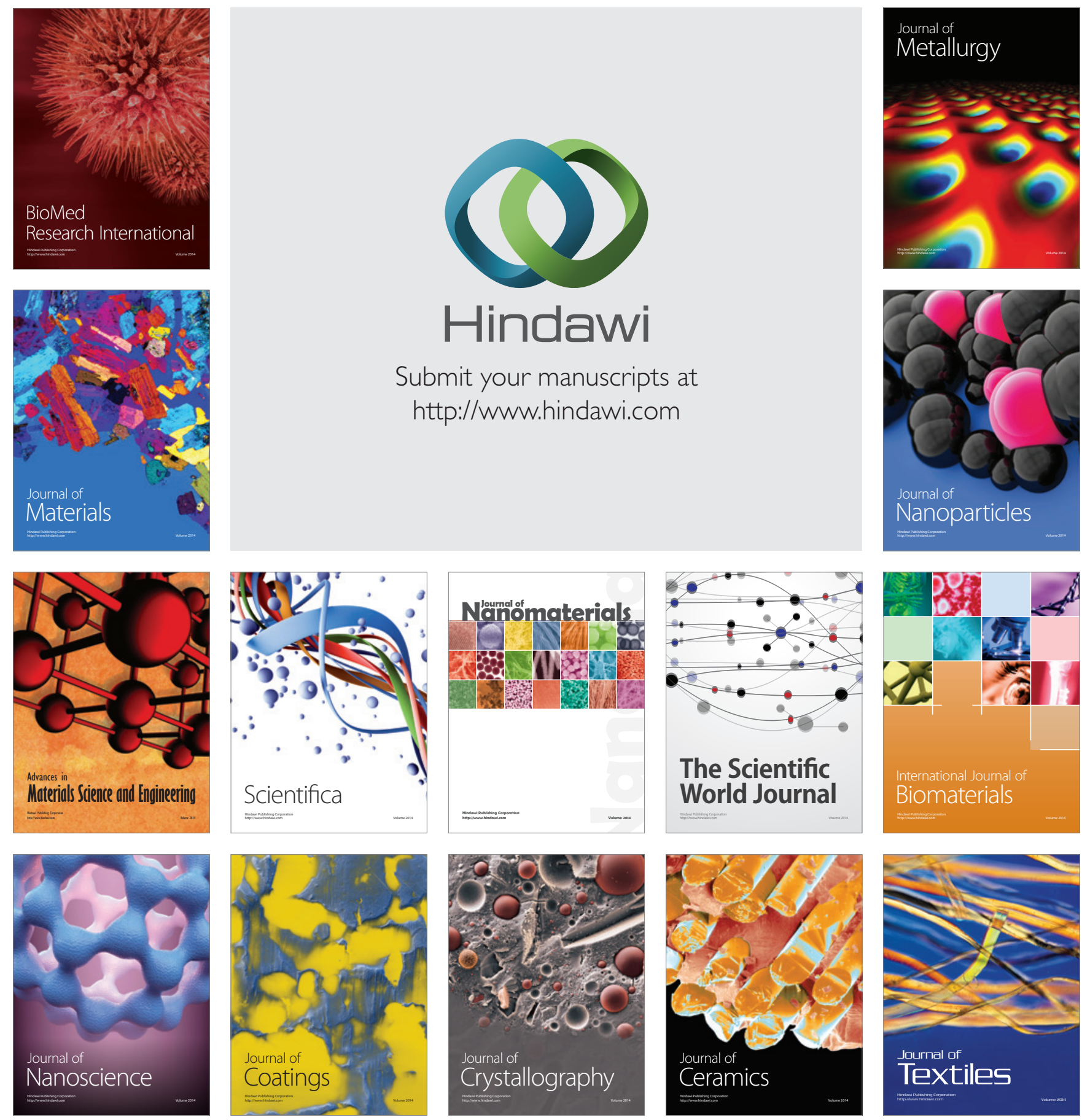